\title{
BMJ Open Quality Evaluation of preprinted consent forms for retinal detachment repair surgery: a short report
}

\author{
Diya Baker, ${ }^{1}$ Mohammad Hamzah Amin (D) ,2 Soon Ch'ng, ${ }^{1}$ Rishika Chaudhary ${ }^{1}$
}

To cite: Baker D, Amin MH, Ch'ng S, et al. Evaluation of preprinted consent forms for retinal detachment repair surgery: a short report. BMJ Open Quality 2021;10:e001264. doi:10.1136/ bmjoq-2020-001264

- Additional material is published online only. To view, please visit the journal online (http://dx.doi.org/10.1136/ bmjoq-2020-001264).

Received 5 November 2020 Revised 21 January 2021 Accepted 7 February 2021

Check for updates

(c) Author(s) (or their employer(s)) 2021. Re-use permitted under CC BY-NC. No commercial re-use. See rights and permissions. Published by BMJ.

${ }^{1}$ Birmingham Midlands Eye Centre, Sandwell and West Birmingham Hospitals NHS Trust, Birmingham, UK

${ }^{2}$ Medicine, University of Birmingham Birmingham Medical School, Birmingham, UK

Correspondence to Mohammad Hamzah Amin; mha604@student.bham.ac.uk

\section{INTRODUCTION}

Autonomy as a pillar of medical ethics is a foundation on which the doctor-patient relationship is established. The consent process for surgery is an example of patient autonomy that is directly exhibited. The consent process should be undertaken vigilantly and with evaluation. It should not be equated to a tick-box exercise, as explained in the Montgomery versus Lancashire Health Board case. ${ }^{1}$

Retinal detachment surgery repair conducted at the Birmingham Midland Eye Centre currently follows a protocol of consent with handwritten forms completed by an ophthalmologist with the patient present. Local issues arose with legibility, missing information and high variability in the documentation. A Comparative analysis with national opinion; the Medical Defence Union stated within ophthalmology allegations commonly centre on an inadequate consent process. ${ }^{2}$ Consequent to these findings, a process of improvement was embarked on in the way of a quality improvement project (QIP). This QIP conformed to the Standards for Quality Improvement Reporting Excellence or SQUIRE V.2.0 guidelines. ${ }^{3}$

Following a literature search, use of a preprinted consent form was found to be successful in orthopaedic surgery, as well as finding numerous improvements with the interventions, such as improved legibility, reduced human error variation and less medical jargon. ${ }^{4}$ No analysis of such measures has been found for retinal detachment surgery repair, and subsequently, this paper aimed to report on such implementation.

\section{METHODOLOGY: FIRST CYCLE}

Senior clinicians noticed several patients had expressed concerns with the current (preprinted) consent forms, namely, their illegibility and lack of risk factor documentation within the consent form. Consequently, a cross-sectional survey was carried out to detect the nature of the underlying issues. This survey questioned patients who provided consent for retinal detachment repair surgery in a specialist tertiary care centre. Patients were offered an anonymous questionnaire consisting of 29 separate questions that aimed to contextualise patients' understanding of the consent process, consent form information and procedure-specific risks. Fifty patients completed the questionnaire and results were analysed in a double-blinded fashion. The project was registered in the local audit register. The outcomes measured in the questionnaires were

- Patient's knowledge of consenting process- average score based on a quiz within the questionnaire

- Patient's wishes documented in the consent form.

- Patients felt all risks are documented in the consent form.

- Patients felt risks were made clear to them.

- Patients felt they understood the consent form wholly.

These outcomes were based on the General Medical Council (GMC) standards ${ }^{5}$ :

44-Before accepting a patient's consent, you must consider whether they have been given the information they want or need, and how well they understand the details and implications of what is proposed.

28-Clear, accurate information about the risks of any proposed investigation or treatment, presented in a way, patients can understand, can help them make informed decisions.

\section{Results: first cycle}

Fifty patients completed the questionnaire. Just over half of the patients understood the consent form wholly, and only $50 \%$ felt the consent form was legible. Twenty-two per cent of the participants agreed not all the risks 
Table 1 Comparison of patient questionnaire results from cycle 1 (handwritten consent forms) and cycle 2 (preprinted consent forms)

\begin{tabular}{lllll}
\hline & $\begin{array}{l}\text { Handwritten } \\
\text { forms, \% (n) }\end{array}$ & $\begin{array}{l}\text { Preprinted } \\
\text { forms, \% (n) }\end{array}$ & Difference & Statistical test (P value) \\
\hline $\begin{array}{l}\text { Patients felt they understood } \\
\text { the consent form wholly. }\end{array}$ & $56(28)$ & $76(38)$ & $20 \%(1.43-36.78)$ & $4.412(0.0357)$ \\
$\begin{array}{l}\text { Patients felt risks were made } \\
\text { clear to them. }\end{array}$ & $42(23)$ & $98(49)$ & $56 \%(39.82-68.73)$ & $36.96(<0.0001)$ \\
$\begin{array}{l}\text { Patients felt all risks } \\
\text { documented. }\end{array}$ & $78(39)$ & $84(42)$ & $6 \%(-9.56$ to 21.30) & $0.579(0.4467)$ \\
$\begin{array}{l}\text { Patients' wishes were } \\
\text { documented. }\end{array}$ & $18(9)$ & $66(33)$ & $48 \%(29.15-62.19)$ & $23.409(<0.0001)$ \\
$\begin{array}{l}\text { Score on knowledge regarding } \\
\text { consenting process }(\%)\end{array}$ & 57 & $62^{*}$ & 5 & $-1.5701(0.1282) \dagger$ \\
\hline
\end{tabular}

*SD.

tt-Value ( $p$ value).

discussed were documented. When quizzed about the consenting process, the average score was $57 \%$.

\section{Methodology: second cycle}

Following discussions with two independent vitreoretinal surgeons, it was decided that a new preprinted consent form should be trialled (see online supplemental material). This was hoped to solve issues with legibility and would ensure all risks are already included. A preprinted consent form was designed by the senior author and trialled.

A second cycle of data collection was undertaken to assess the new preprinted consent forms using the same questionnaire with five questions amended to include the term preprinted procedure-specific consent form. A simple randomisation process via coin toss selected patients for the new preprinted consent forms. These patients were unaware of the existence of handwritten consent forms or even that a new consent form was being trialled. The results were compared with the first cycle. $(\mathrm{N}-1) \chi^{2}$ test was used to calculate statistical significance as recommended by Campbell. ${ }^{6}$ The statistical significance for the average score when quizzed about the consenting process was calculated using t-test.

\section{RESULTS}

Participants were patients undergoing retinal detachment. The results are listed in table 1 . There was a $20 \%$ increase in patients who completely understood the preprinted consent form. There was a $56 \%$ increase in patients who thought the preprinted consent forms made the risks clearer. There was a $48 \%$ increase in patients who thought the preprinted consent form documented their wishes. All of these results were statistically significant with a $\mathrm{p}$ value of $<0.05$.

There were no statistically significant differences between the two forms in documenting all the risks. The average score when quizzing the participants on the consenting process did not improve significantly with the new consent form.

From these results, one can conclude that the preprinted consent forms are an improvement in the consenting process as they are easier to understand; they make the risks clearer to the patient; and they document the patient wishes more effectively. Ninety-four per cent of the participants agreed they preferred preprinted forms over handwritten ones.

These findings were presented to ophthalmologists at the local quality improvement meeting, where it was decided to incorporate preprinted consent forms into departmental practice. This is now in use as local standard practice for retinal detachment surgery.

\section{DISCUSSION}

This project found preprinted consent forms improve patient experience and understanding. One of the key features is legibility, which can be poor in handwritten consent forms. The reason for this may be time pressure on clinicians. By introducing preprinted consent forms, legibility is markedly improved. As there is less to write, the consenting process is more efficient, and clinicians have a lesser time burden.

The study design aimed to capture the subjective experiences of the participants. Patients' experience of the consent form is a subjective experience, and their understanding of the consent form was assessed in a subjective fashion. Owen et al employed a more objective approach to measure improvement as they measured legibility and information within consent forms retrospectively. ${ }^{4}$ The principal limitation of this subjective approach is that one cannot objectively conclude preprinted consent forms to be more effective. However, the evaluation of patients' experience clearly concluded preprinted consent forms to be superior in the patient's point of view. As a result, the benefit of a subjective design is patients' perspectives are understood when determining the quality of consent, 
and subsequently acting on these viewpoints in a safe and efficacious manner.

There are numerous learning points to hallmark from this project.

Despite the data collection being carried out during the COVID-19 pandemic, there was little hindrance to the data collection. This was because fortuitously, retinal detachment surgery continued at this tertiary centre during the first wave of the pandemic. Second, designing the consent form was an efficient process due to the combined experience and familiarity with retinal detachment surgery, possessed by the senior authors.

Among the key problems faced was incorporation of the novel form into common use within common practice. We addressed the first step of incorporation by presenting the findings to the local team.

Although regular monthly quality improvement meetings were initially cancelled, these meetings were reinstated in a remote fashion. The findings were presented and incorporation into departmental practice was accepted. The second step was to organise a provider of the consent forms who will regularly print the consent forms to prevent shortages in clinical practice. Although a laborious process initially, this preprinted consent form was added as a stock template which streamlined the process. Strong communication with stock managers was vital throughout the implementation of the new consent forms, and as a result, deliveries were easily arranged, and the stock was placed in a location easily accessible by clinicians.

We hypothesise the findings of this study are applicable to other surgical procedures in ophthalmology; however, further data collection to empirically prove this will be required. The Royal College of Ophthalmologists also advise the use of procedure-specific prepopulated consent forms. ${ }^{7}$

Approximately three-quarters of respondents agreed to reading the consent form and understanding the content. However, some patients were not able to read the questionnaire due to poor vision; instead, the questionnaire was read out to them. This questions their ability to read the preprinted consent forms. Perhaps, more innovative ideas are required to aid the consenting process for ophthalmology patients.
Contributors DB and MHA wrote the report and did the data collection. RC and $\mathrm{SC}$ had an advisory role and also designed the improvement in the quality improvement project.

Funding The authors have not declared a specific grant for this research from any funding agency in the public, commercial or not-for-profit sectors.

Competing interests None declared.

Patient consent for publication Not required.

Provenance and peer review Not commissioned; externally peer reviewed.

Supplemental material This content has been supplied by the author(s). It has not been vetted by BMJ Publishing Group Limited (BMJ) and may not have been peer-reviewed. Any opinions or recommendations discussed are solely those of the author(s) and are not endorsed by BMJ. BMJ disclaims all liability and responsibility arising from any reliance placed on the content. Where the content includes any translated material, BMJ does not warrant the accuracy and reliability of the translations (including but not limited to local regulations, clinical guidelines, terminology, drug names and drug dosages), and is not responsible for any error and/or omissions arising from translation and adaptation or otherwise.

Open access This is an open access article distributed in accordance with the Creative Commons Attribution Non Commercial (CC BY-NC 4.0) license, which permits others to distribute, remix, adapt, build upon this work non-commercially, and license their derivative works on different terms, provided the original work is properly cited, appropriate credit is given, any changes made indicated, and the use is non-commercial. See: http://creativecommons.org/licenses/by-nc/4.0/.

ORCID iD

Mohammad Hamzah Amin http://orcid.org/0000-0001-9007-3059

\section{REFERENCES}

1 UKSC. Montgomery V Lanarkshire health board [2015] UKSC 11, 2015.

2 Themdu.com. Claims in ophthalmology - The MDU [Internet], 2020. Available: https://www.themdu.com/guidance-and-advice/guides/ claims-in-ophthalmology [Accessed 11 Oct 2020].

3 Ogrinc G, Davies L, Goodman D, et al. Squire 2.0 (standards for quality improvement reporting excellence): revised publication guidelines from a detailed consensus process. BMJ Qual Saf 2016;25:986-92.

4 Owen D, Aresti N, Mulligan A, et al. Customizable pre-printed consent forms: a solution in light of the Montgomery ruling. Br J Hosp Med 2018;79:97-101.

5 Gmc-uk.org. GMC [Internet], 2020. Available: https://www.gmc-uk. org/-/media/documents/gmc-guidance-for-doctors-consent-english pdf-48903482.pdf?la=en\&hash=588792FBA39749E57D881FD2E33A 851918F4CE7E [Accessed 11 Oct 2020].

6 Campbell I. Chi-squared and Fisher-Irwin tests of two-by-two tables with small sample recommendations. Stat Med 2007;26:3661-75.

7 Rcophth.ac.uk. RCOphth. [Internet], 2020. Available: https://www. rcophth.ac.uk/wp-content/uploads/2020/05/Standards-of-consentfor-ophthalmology-procedures-during-the-Covid-pandemic.pdf [Accessed 26 Oct 2020]. 